\title{
Artisanship, Meritocracy, and Apathy
}

\author{
Masayuki Otaki ${ }^{1}$ \\ Institute of Social Sciences, the University of Tokyo \\ ohtaki@iss.u-tokyo.ac.jp
}

\begin{abstract}
This study presumes the bounded rationality of cognition concerning the way of life. People called artisans feel higher felicity whenever they produce more refined goods. In contrast, those dubbed capitalists are devoted to maximizing their profits. People in an economy choose which way of life they send. We assume that meritocratic education mostly nurtures capitalists. However, such education is superficial or even harmful in the sense that the true happiness of a human being comprises not only pecuniary benefits but also job satisfaction. In other words, efficiency pecuniary measurement of efficiency is not impartial, and if people are apt to behave under such a standard of value, some level of apathy prevails, as observed in the current world economy. This study found that the state wherein all individuals become artisans is an evolutionary stable set (ESS). People not merely achieve a higher satisfaction from completing their jobs, but also prosper materialistically, as high-quality goods are produced and exchanged within the economy. This suggests an urgent need to reconstruct a social norm, which controls meritocratic behavior through democratic education procedure.
\end{abstract}

Keywords: Artisanship; Meritocratic Education; Apathy; Social Norm; Bifurcation of Equilibrium JEL Classifications: 121 ; 128

\section{INTRODUCTION}

Today, most individuals in advanced economies are bothered by apathy. They are vague about their job aims and finding positive values in life. Where does such apathy come from? This study examines why apathy is prevalent in advanced economies, based on the concept of bounded rationality and evolutionary game theory.

As Otaki (2015) points out, it is a plausible assumption that no individual can fully maximize his utility function because of the limit of cognition. Consequently, each individual must choose his lifestyle, which is defined by the factor maximized. Similar to Otaki (2015), this study divides the way of life into two types; artisan and capitalist. An artisan maximizes the quality of his producing goods to the extent that his minimal living standard is guaranteed. On the other hand, the primary concern of a capitalist is his profits and the quality of goods is secondary. The true total utility comprises the sum of the quality of produced goods and earned profits.

At least two Evolutionary Stable Sets (ESSs) exist. One is an economy where all individuals are artisans. The other is an economy that entirely consists of capitalists. The former is an ESS because every individual can consume high-quality goods, and thus, they can concentrate on how to achieve the fullness of life that is defined as producing the most furnished goods. The latter is also an ESS. When an economy is filled with capitalists, no individual moves to an artisan-type life because his elaboration is not well-received and he is forced to exchange low-quality goods for his refined goods. This is the main result of Otaki (2015).

Since the artisan-occupying ESS is Pareto dominant, individuals feel some vague dissatisfaction whenever the economy remains in the capitalist-occupying ESS. Because profit motive is the norm of the economy, individuals hardly find another type of economy, in which social cohesion and confidence exist. We dub such vague dissatisfaction apathy. This is a type of alienation that hinders the accumulation of mutual confidence in human behavior.

\footnotetext{
${ }^{1}$ The author is thankful for the participants to the seminar at Research Institute of Capital Formation in Development Bank of Japan. Especially, the critical but incisive comments of Takashi Unayama refine the contents of this study. Needless to say, possible remaining errors are entirely attributed to the author. This study is supported by MEXT/JSPS KAKENHI Grant Number 60183761.
} 


\section{Masayuki Otaki}

This study examines how an ESS is chosen in reality. The existing social norm and education play a crucial role. We also emphasize the tangibility of education. Social norm is self-enforcing once it exceeds a certain threshold. Children are affected by their parents because they observe and mimic the adults' social and economic behavior. If a particular behavior gains prominence and is frequently observed, it becomes widespread among descendants. As such, a social norm is self-enforcing and becomes a spontaneous order in Hayek's sense. The foregoing discussion about the artisan-occupying and capitalist-occupying ESSs is a typical example.

Besides this self-enforcing mechanism, education plays an important role in directing where the social norm evolves. In contrast with autonomous order, education is designed based on imperfect human knowledge. Metaphorically, it seems that there are two types of education. One is the prevalent meritocratic education, which emphasizes ability and achievement. The other to be accentuated is a new type of artisanship.

There is no denying that meritocratic education significantly contributes to the modernization or development of an economy. However, it should be noted that this type of education is apt to exaggerate its own tangible fruits; for example, scores in examinations and which college one graduates from. Such type of education nurtures not only the nexus of useful abilities, which might be indispensable for the current business world, but also lessens the ability to understand truth structurally from the bottom. Accordingly, such short-sighted education obliges people to become restless and purposeless. Even politics and economics, few possess the deep and consistent insight of society and economy, resulting in confusing, society is disrupted by their hodge-podge policies. As such, citizens who do not receive sufficient education also become restless and aspire that their children rise through meritocratic education. Thus, all individuals are entrenched by apathy.

Repetition and reconstruction are the vital concepts of this study. Dewey (1916) emphasized the role of experience in education. As a prominent pragmatist, he proposed that by systemizing experience for children, they can be given the structural knowledge. Nevertheless, Dewey's experimental elementary school was not sustainable. This fact suggests that his education program did not work well. Moreover, it is undeniable that the exiting artisanship demands unnecessary and unreasonable hardships for children. In this sense, Dewey's assertion is valid to reformulate the pre-modern artisanship.

However, what Dewey overlooks is the diversity of children. Even though income level and social stratum to which their parents belong are affine, children's cognition patterns are quite diversified. Presuming such diversity, teachers have the responsibility to help their students realize simple truth, and those which seem different and/or unrelated are governed by simple principles.

To achieve the goal, repetition by elaborated variations of the same subject is desirable. Hindering the saturation of students and concentrating on the same theme, this kind of repetition is unavoidable. Ascertainment of the reconstruction ability of the learned subject is also crucial for the new artisanship education. By reconstruction of the concept taught, students acquire structural knowledge on the subject. This is because a student cannot achieve the reconstruction without understanding the composition of the subject and integrating the debris of experiences. The teacher must note that the expressions and presentations differ from one student to another. As long as these reconstructions are consistent, the teacher must not force the identical expression because such differences signify the diversity of students' cognition pattern.

Initially, the dealt subject should be elementary in the sense that the distance between inference and abstraction is not far. This is because students require sufficient accumulation of learning experience to be patient to bear more complicated intellectual training. We must acutely realize that the ultimate aim of this type of education is to nurture the intellectual curiosity in the true sense that education facilitates students to find their own callings. As individuals, whose works are well-suited for themselves, increase, the social norm, which regards making money as only the consequence of their social contribution, would prevail instead of meritocracy. Gradually, education affects the social norm of an economy.

The dynamic manner in which education alters the social norm is depicted by the theoretical bifurcation of equilibrium. For example, assume that there is an ESS wherein artisans and capitalists coexist. In general, the tangibility of achievement of education possibly prompts the meritocratic style rather than the new-artisan style. This is because earned profits are a convenient measure for assessing 
individuals' abilities in contrast with the evaluation of quality of produced goods. A government, which strives to accelerate economic development (in developing economies), or is urged to recover from a prolonged stagnation (in developed economies), is attracted to this type of education.

Under such a situation, the artisan population gradually decreases because they become more reluctant to trade with capitalists who produce low-quality goods due to the meritocratic behavior. When a decrease in artisan population exceeds a certain critical value, the foregoing equilibrium is unsustainable and vanishes, since artisans cannot be patient in such a situation due to their poor economic condition. Thus, the coexisting equilibrium vanishes and all potential artisans metamorphose to capitalists. In economic theory, such a drastic change in economic condition is called bifurcation. It is evident that educational policy possibly evolves the social norm as such.

To summarize, a social norm is generated by the self-enforcing power. This self-enforcing power originates from the high frequency of observation of a specific way of life. For example, whenever meritocratic way of life becomes more prevalent, individuals in the society have many opportunities to encounter and informally learn such a way of life, consequently, they become to regard this as the new norm.

Education is vital to determine toward which norm a society progresses. This is because education nurtures the foundation of value judgment and the rules of thumb in one's life. If a society wishes to avoid the aforementioned apathy, whereby constituents cannot feel cohesion, new-artisanship should be introduced in the education system. However, as the foregoing bifurcation theory tells us, unfatigued and intelligent efforts are required for such a reformation.

This study is organized as follows. Section 2 constructs a model that shows how a social norm is generated based on an evolutionary game with bounded rationality. Section 3 considers the role of education in altering the social norm by using the bifurcation theory. Section 4 offers brief concluding remarks.

\section{THE MODEL}

\subsection{The Basic Game}

Let us consider a production economy in which self-consumption is prohibited. This assumption implies that there exist infinite kinds of goods and that exchange is unavoidable to obtain the favorite goods. This means, in turn, producing high-quality goods is a contribution to the overall society because this behavior is beneficial for trading partners.

The total utility of an individual, $U_{i}$, is

$U_{i} \equiv u\left(q_{j}\right)+q_{i}-c\left(q_{i}\right), \quad i \neq j, q \geq 0$

$u(0)=c(0)=0,0<u^{\prime}<1, u^{\prime \prime}<0, c^{\prime}, c^{\prime \prime}>0, \lim _{q \rightarrow \infty} u^{\prime}=0, \lim _{q \rightarrow 0} c^{\prime}=0, \lim _{q \rightarrow \infty} c^{\prime}=\infty$,

where $u$ is the utility obtained from exchanged goods and $c$ denotes the cost for producing goods. $q_{i}$ is the quality of goods. The second term of Equation (1) indicates that an individual feels felicity from producing high quality goods, which implies that he potentially has the interest in contributing to society's wellbeing through sincere behavior.

Individuals are assumed to be bounded rational and cannot fully maximize their utility. That is, two types of individual exist in this economy: artisan and capitalist. An artisan concentrates on maximizing his partial utility obtained from producing high quality goods to the extent that he can manage his daily life, whoever his counterpart is. This assumption implies that an artisan is more socialized in the sense that he indirectly contributes to the overall society by providing high-quality goods, although this contribution is beyond his cognition.

Accordingly, his economic behavior is defined as

$$
\max _{q_{i}}\left[q_{i}-c\left(q_{i}\right)\right] \text {, s.t. } u\left(q_{j}\right)-c\left(q_{i}\right) \geq 0 \text {. }
$$

Whenever his counterpart belongs to the same type of individuals, the nonnegative constraint is redundant by Inada condition in Equation (1) and the equilibrium strategy, $q^{H}$, simply becomes 
$c^{\prime}\left(q^{H}\right)=1$

Otherwise, by Kuhn-Tucker theorem, the equilibrium strategy, $q^{A}$, becomes

$u\left(q_{j}\right)-c\left(q^{A}\right)=0, u\left(q_{j}\right)-c\left(q^{H}\right)<0$.

Equation(4) yields

$q^{A}<q^{H}$.

This inequality implies that the quality of goods exchanged among artisans is superior to those between artisans and capitalists.

A capitalist is assumed to maximize joint utility whenever he encounters the same type of individual, which implies that he is not directed to the widespread social concern, but the reciprocal relationship. Thus, the maximization problem when he encounters another capitalist is

$$
\max _{q}[u(q)-c(q)] \text {. }
$$

The corresponding necessary-sufficient condition is

$$
u^{\prime}\left(q^{L}\right)=c^{\prime}\left(q^{L}\right) \text {. }
$$

When a capitalist encounters an artisan, he writes the following contract with the artisan.

$$
\max _{q^{C}, q^{A}}\left[u\left(q^{A}\right)-c\left(q^{c}\right)\right] \text {, s.t. (4), }
$$

where $q^{A}$ and $q^{c}$ are the quality of goods which an artisan and a capitalist produce, respectively.

The equilibrium contract satisfies

$$
u\left(q^{c^{*}}\right)-c\left(q^{A^{*}}\right)=0, u\left(q^{L}\right)-c\left(q^{A^{*}}\right) \leq 0 \Rightarrow u\left(q^{L}\right)-u\left(q^{c^{*}}\right) \leq 0,
$$

if the constraint is binding. $q^{c^{*}}$ is the optimal quality of a capitalist provides when he encounters an artisan. $q^{A^{*}}$ is that of an artisan when he matches a capitalist. It should be noted that, from Equation (10), that

$$
q^{c^{*}} \geq q^{L}
$$

is upheld.

Moreover, if $q^{c^{*}} \geq q^{H}$, all artisans produce quality $q^{H}$ goods, since their constraint (4) is redundant. However, the counterpart capitalist can consume such goods without paying any compensation. Accordingly, the budget constraint of all artisans is violated. Thus, this is a contradiction due to assuming $q^{c^{*}} \geq q^{H}$.

Therefore, it is clear that

$$
q^{L} \leq q^{c^{*}}<q^{H}
$$

is upheld.

Similarly, if $q^{A^{*}}<q^{L}$,by inequality (10),

$$
u\left(q^{L}\right)-c\left(q^{L}\right)<u\left(q^{L}\right)-c\left(q^{A^{*}}\right)<0,
$$

holds. This inequality contradicts $u\left(q^{L}\right)-c\left(q^{L}\right) \geq 0$. Accordingly, $q^{A^{*}}>q^{L}$. Combining the above result with Inequality (5), we obtain 
$q^{L} \leq q^{A^{*}}<q^{H}$.

Inequalities (12) and (14) imply that goods exchanged between artisans are superior in quality to those exchanged between capitalists.

Finally, if $q^{c^{*}} \geq q^{A^{*}}$, this implies $u\left(q^{c^{*}}\right)-c\left(q^{A^{*}}\right)=0$. Thus, we obtain $u\left(q^{A^{*}}\right)-c\left(q^{c^{*}}\right) \leq 0$. This inequality contradicts the assumption of interior solution of the contract problem. Consequently,

$q^{c^{*}}<q^{A^{*}}$.

From Inequalities (12), (14) and (15), we obtain the payoff matrix as shown in Table 1and the quality order of produced commodities:

Table1. The Payoff Matrix

\begin{tabular}{c|c|c} 
& & \\
Player & Artisan & Capitalist \\
\hline Artisan & $u\left(q^{H}\right)+q^{H}-c\left(q^{H}\right), u\left(q^{H}\right)+q^{H}-c\left(q^{H}\right)$ & $q^{A *}, u\left(q^{A *}\right)+q^{c *}-c\left(q^{c *}\right)$ \\
Capitalist & $u\left(q^{A *}\right)+q^{c *}-c\left(q^{c *}\right), q^{A *}$ & $u\left(q^{L}\right)+q^{L}-c\left(q^{L}\right), u\left(q^{L}\right)+q^{L}-c\left(q^{L}\right)$
\end{tabular}

$q^{L} \leq q^{c^{*}}<q^{A^{*}}<q^{H}$.

In addition, we assume that

\section{Assumption 1.}

The additional utility obtained by upgrading the quality is small enough and

$u\left(q^{L}\right)-c\left(q^{L}\right)>q^{A^{*}}-q^{L}$,

holds.

This assumption implies that additional utility obtained by refining the skills for production is less attractive than the remaining profit-centered motivation.

Based on Table 1, we obtain the following theorems ${ }^{2}$

\section{Theorem 1.}

Let $\theta$ denote the ratio of artisans who occupy the economy. Then, $\theta=1$ is an ESS of this evolutionary game.

\section{Proof.}

Let the payoff function be denoted as $\pi(x, y)$, where an individual strategy $x$ and his counterpart choses strategy $y \cdot x$ and $y$ take the value 1 (play artisan)and 2 (play capitalist), respectively. By definition, the necessary-sufficient condition for $\pi(1,1)$ being an ESS is that there is a neighborhood $(0, \varepsilon)$ such as

$\pi\left(1,\left[1-\varepsilon^{\prime}\right] \cdot 1+2 \cdot \varepsilon^{\prime}\right),>\pi\left(2,\left[1-\varepsilon^{\prime}\right] \cdot 1+2 \cdot \varepsilon^{\prime}\right), \forall \varepsilon^{\prime} \in \varepsilon$.

Inequality (18) is equivalent with

$$
\pi(1,1)>\pi(2,1) \text {. }
$$

Since

$$
\pi(1,1)=u\left(q^{H}\right)+q^{H}-c\left(q^{H}\right), \pi(2,1)=u\left(q^{A^{*}}\right)+q^{c^{*}}-c\left(q^{c^{*}}\right),
$$

\footnotetext{
${ }^{2}$ Weibull (1995) is a useful textbook about evolutionary game theory.
} 
Since $q^{H}-c\left(q^{H}\right)>q^{c^{*}}-c\left(q^{c^{*}}\right)$ by definition, Inequality (19) is upheld. This completes the proof.

Theorem 2.

$\theta=0$ is another ESS.

Proof.

Similar to Theorem 1, the necessary-sufficient condition is

$$
\pi\left(2,\left[1-\varepsilon^{\prime}\right] \cdot 2+1 \cdot \varepsilon^{\prime}\right),>\pi\left(1,\left[1-\varepsilon^{\prime}\right] \cdot 2+1 \cdot \varepsilon^{\prime}\right), \forall \varepsilon^{\prime} \in \varepsilon .
$$

Then, Inequality (21) is equivalent with

$$
\pi(2,2)>\pi(1,2) \text {. }
$$

Since

$$
\begin{aligned}
& \pi(2,2)=u\left(q^{L}\right)+q^{L}-c\left(q^{L}\right), \pi(1,2)=u\left(q^{c^{*}}\right)-c\left(q^{A^{*}}\right)+q^{A^{*}}=q^{A^{*}} \\
& \pi(2,2)-\pi(1,2)=\left[\left[u\left(q^{L}\right)-c\left(q^{L}\right)\right]-\left[q^{A^{*}}-q^{L}\right]\right]>0,
\end{aligned}
$$

as far as Assumption 1 is satisfied, Inequality (22) holds. This completes the proof.

\subsection{Formation of Social Norm and Multiple Frictional ESSs}

Otaki (2015) analyzes the selection of the foregoing two ESSs by using the replicator dynamics. However, this analysis is rather mechanical and lacks the background for the reason why such an equilibrium selection mechanism works. Rather than the replicator dynamics, this study considers a more profound source of evolution of a society and points out the possibility of multiple frictional ESSs.

Frictional ESS is defined as follows:

\section{Definition 1.}

A frictional ESS is an ESS wherein some individuals still choose not to play the evolutionary stable strategy. That is, for some $\varepsilon>0$ and for all $\varepsilon^{\prime}$ such as $0<\varepsilon \mid<\varepsilon^{\prime}, \theta$ exists that satisfies the following inequality:

$$
\pi\left(x,\left[\theta-\varepsilon^{\prime}\right] x+\left[1-\theta+\varepsilon^{\prime}\right] y\right)>\pi\left(y,\left[\theta-\varepsilon^{\prime}\right] x+\left[1-\theta+\varepsilon^{\prime}\right] y\right), 0<\theta<1,
$$

where $x$ is an evolutionary stable strategy and $y$ is the mutant strategy.

Frictional ESS is an indispensable concept not to collapse the sequence of transition equilibrium. For clarifying the meaning of frictional ESS, let us classify how an individual's strategy alters in accordance with which type of player he encounters. There are four matching cases: artisan versus artisan; artisan versus capitalist; capitalist versus artisan; and capitalist versus capitalist. It is assumed that whenever the same type of individuals (artisan versus artisan and capitalist versus capitalist) encounters, their or their children's behavior is unchanged because they achieve the best outcome that satisfies their bounded rationality.

The problem arises when different types of individuals are matched. In such a case, both types of individual encounter the conflict of the value of the way of life. It must be noted that ethos exists, which is not easily affected by the short-run economic benefits. Accordingly, even though the benefits earned by behaving as a capitalist dominate those as an artisan, when an artisan matches with a capitalist, only some children of artisans alter their way of life. Let this staying ratio (the ratio of the children of artisans who remain artisan) be denoted as $\Lambda_{1}\left(\theta_{t}\right) . \Lambda_{1}$ is an differentiable function of $\theta_{t}$. Similarly, when a capitalist encounters an artisan and find that switching his way of life is meaningful, some their children change their lives. Let us denote the switching ratio $\Lambda_{2}\left(\theta_{t}\right) \cdot \Lambda_{2}$ is also assumed to be a differentiable function. ${ }^{3}$

${ }^{3}$ More explicitly, the difference in the individuals' propensity might be introduced into the utility function such

$U_{j} \equiv u\left(q_{i}\right)+q_{j}-c\left(q_{j}\right)+\lambda_{j}(\theta), \Lambda_{1}(\theta) \equiv \int_{\lambda_{j} \geq \kappa} \lambda_{j}(\theta) d F(j)$, 
Thus, we define

$$
\Lambda\left(\theta_{t}\right) \equiv \Lambda_{1}\left(\theta_{t}\right)+\Lambda_{2}\left(\theta_{t}\right)
$$

It must be noted that

$$
\Lambda(0)=\Lambda_{1}(0)+\Lambda_{2}(0)=0+0=0, \Lambda(1)=\Lambda_{1}(1)+\Lambda_{2}(1)=1+1=2,(28)
$$

holds because $\theta=0,1$ are ESSs. The dynamics of the occupying rate of artisan in the economy $\theta_{t}$ evolves by the following difference equation:

$$
\theta_{t+1}=\theta_{t}^{2}+\theta_{t}\left[1-\theta_{t}\right] \Lambda\left(\theta_{t}\right) \text {, }
$$

The first term of Equation (29) is the probability of (artisan, artisan) pair being combined. The second term is the sum of the probability that an artisan remains in the same way of life even though he encounters a capitalist and the probability that a capitalist change his way of life by becoming aware of an alternative life style.

Equation (29) determines the dynamics of the social norm in the sense that which way of life people are likely to prefer. Let function $f$ be defined as

$$
f(\theta) \equiv \theta^{2}+\theta[1-\theta] \Lambda(\theta) \text {. }
$$

From Equation (22), we obtain

$$
f^{\prime}(0)=0, f^{\prime}(1)=2+[1-2] \cdot 2=0 \text {. }
$$

$f$ is a continuous function within $[0,1]$. Accordingly, as illustrated in Figure $1, f$ has, at least, one other intersection with the $45^{\circ}$ line than at $\theta=0,1$.

In such a case as shown in Figure 2, the economy converges to either artisan-occupying ESS ( $\theta=1)$ or capitalist-occupying ESS ( $\theta=0$ ). To which of the ESSs the economy converges is determined by its history. Here, history means the initial occupying ratio $\theta_{0}$.However, such an assertion is rather improper because there were some drastic shifts in social norm, as Riesman (1950) summarizes succinctly. In addition, it is plausible to regard that artisanship and profit-centered motive, more or less, coexist at any time. Therefore, more prudent analysis is necessary. In the next section, we consider a more general case of the evolution of social norm, and reveal how education affects the organization of social norm.

In preparation for the study, the following theorem is convenient.

\section{Theorem 3.}

Artisan-occupying $\operatorname{ESS}(\theta=1)$ dominates capitalist-occupying $\operatorname{ESS}(\theta=0)$ in the Pareto sense.

\section{Proof.}

Since

$\pi(1,1)=u\left(q^{H}\right)+q^{H}-c\left(q^{H}\right), \pi(2,2)=u\left(q^{L}\right)+q^{L}-c\left(q^{L}\right)$,

and

$q^{H}-c\left(q^{H}\right)>q^{L}-c\left(q^{L}\right)$

where $\lambda_{j}(\theta)$ is the propensity to favor artisanship who are born as artisan, and $\kappa$ is defined as a critical value, which corresponds to the excess return obtained by changing the lifestyle from artisan to capitalist:

$\kappa \equiv\left[u\left(q^{A^{*}}\right)-c\left(q^{c^{*}}\right)+q^{c^{*}}\right]-q^{A^{*}} \geq 0$.

It must be noted that $\frac{d}{d \theta} \int_{\lambda_{j} \geq \kappa} \lambda_{j}(\theta) d F(j)$ possibly takes a negative value at least locally because when $\theta$ increases to some extent, the number of those who less prefer artisanship (who possesses a low value of $\lambda$ ) interact with capitalist more frequently; and thus, $\Lambda_{1}(\theta)$ is not necessarily monotonous increasing. $\Lambda_{2}$ is also defined by the same way. 
holds, $\pi(1,1)>\pi(2,2)$. This inequality completes the proof.

This theory implies that if profit-centered behavior prevails in the overall economy, individuals feel some vagueness due to the alienation from the cohesion obtained by pursuing quality. We call this vagueness apathy. Nevertheless, once a society is immersed by profit-centered motivation, owing to the bound rationality of human beings, most constituents cannot pursuit the origin of apathy; and thus, the society is entrapped in a vicious cycle for a long time.

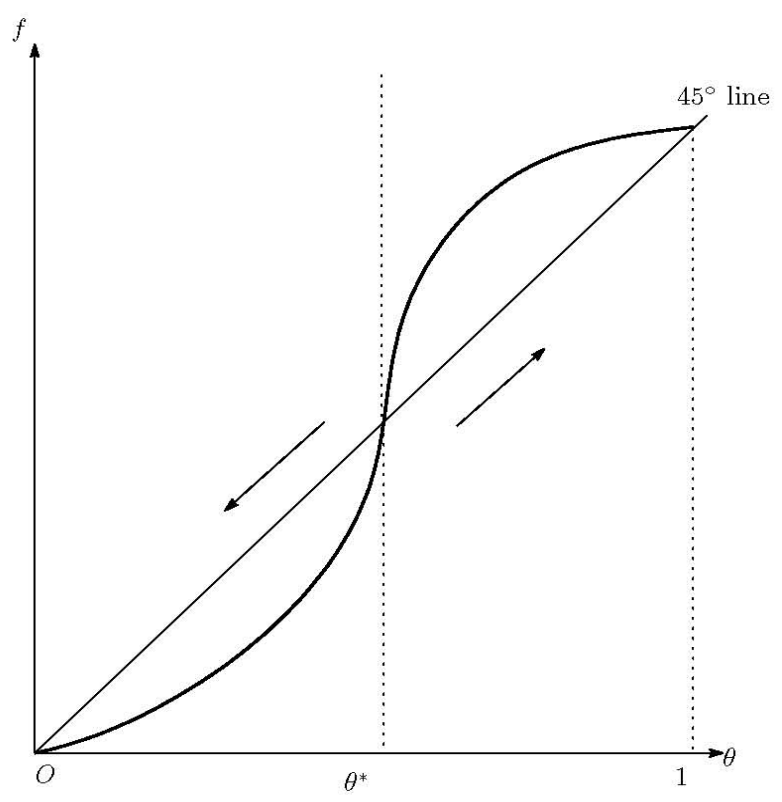

Figure1. Formation of Social Order

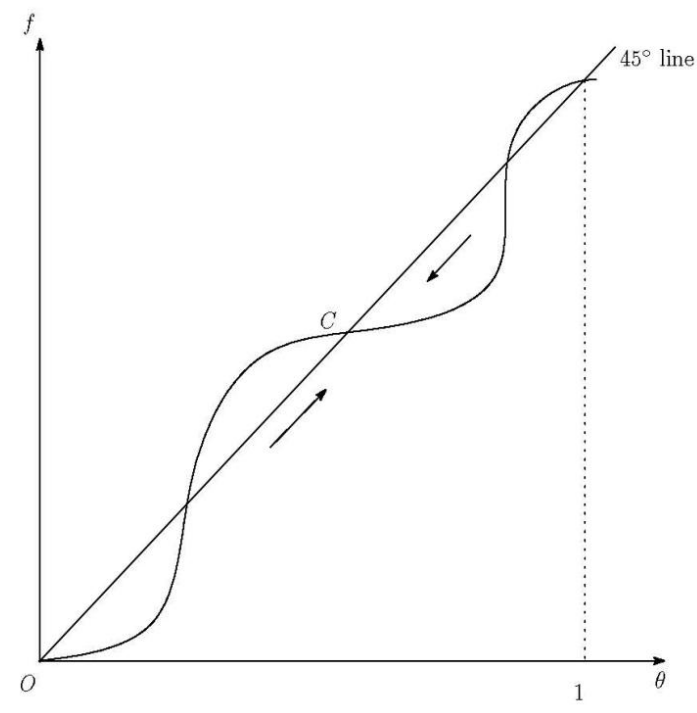

Figure2. Coexisting Equilibrium

\section{Coexistence of Artisan and Capitalist and the Role of EduCation}

\subsection{The Coexistence ESSs}

When $f(\theta)$ takes shape as shown in Figure 2, the coexistence of artisan and capitalist can be depicted by Point $C\left(\theta=\theta^{C}\right) .{ }^{4}$ In such cases, Point $C$ is a stable frictional ESS as the arrows in the figure indicate. From Inequality (20), an elementary calculation leads us to the following lemma:

\footnotetext{
${ }^{4}$ Since Point $C$ is a stable fixed point, the following conditions must be satisfied. That is,
} 


\section{Lemma 1.}

If

$$
0 \leq \theta^{*}<\frac{\pi(2,2)-\pi(1,2)}{[\pi(1,1)-\pi(2,1)]+[\pi(2,2)-\pi(1,2)]},
$$

holds, the frictional ESS is dominated by the way of life of the capitalist. The dominance implies that capitalist type strategy is an evolutionary stable policy. In contrast,

$$
\frac{\pi(2,2)-\pi(1,2)}{[\pi(1,1)-\pi(2,1)]+[\pi(2,2)-\pi(1,2)]} \leq \theta^{*} \leq 1
$$

implies that the frictional ESS is dominated by the way of life of artisan.

The coexistence in capitalist-dominating frictional ESS comes from devotement to artisanship. Even though sticking to artisanship is economically disadvantageous when capitalist style prevails to some extent, as Theorem 2 advocates, some people emphasize on keeping artisanship itself. However, artisanship in such situation disrupts the social order, as will be proved in Theorem 4 .

Conversely, if Point $C$ is located at the artisan-dominating ESS, the economy faces to an opportunity to improve performance, at least locally. An increase in the number of artisans provides more advantageous opportunities wherein high-quality goods are distributed among artisans.

Although Theorem 3 clarifies that the artisan-occupying ESS dominates the capitalist-occupying ESS, we do not know the economic welfare of the coexistence ESS yet. The overall welfare of the society at an ESS (we assume that utility is cardinal), $T U(\theta)$, becomes

$$
\begin{aligned}
& T U(\theta) \equiv \pi(1,1) \theta^{2}+[\pi(1,2)+\pi(2,1)] \theta[1-\theta]+\pi(2,2)[1-\theta]^{2} \\
& =[[\pi(1,1)-\pi(2,1)]+[\pi(2,2)-\pi(1,2)]] \theta^{2}-2\left[\pi(2,2)-\frac{\pi(1,2)+\pi(2,1)}{2}\right] \theta+\pi(2,2) .
\end{aligned}
$$

Accordingly, from Assumption $1^{5}$,

$$
\begin{aligned}
& \Lambda\left(\theta^{C}\right)=1, \\
& f^{\prime}\left(\theta^{C}\right)=1+\theta^{C}\left[1-\theta^{C}\right] \Lambda^{\prime}\left(\theta^{C}\right)<1 \Rightarrow \Lambda^{\prime}\left(\theta^{C}\right)<0 .
\end{aligned}
$$

The shape of $f(\theta)$ is affected by two social factors. One is the self-organization power of a society, which implies that the number of artisan increase along with the higher value of $\theta$ because new generation observe and is affected by the artisan-type way of life more frequently. The second factor is the ethos of capitalist, which means that there are some people who genetically prefer to become capitalist. Although the first factor dominates the second around $\theta=0,1$, the converse is possibly true at least locally. This corresponds that $\Lambda(\theta)$ decreases at least locally, for example, because there are non-negligible capitalists who resist the main stream of the society, which we dub ethos.

${ }^{5}$ The following inequality holds:

$$
\begin{aligned}
& \pi(2,2)-\frac{\pi(1,2)+\pi(2,1)}{2}=u\left(q^{H}\right)+q^{H}-c\left(q^{H}\right)-\frac{q^{A^{*}}+u\left(q^{A^{*}}\right)+q^{c^{*}}-c\left(q^{c^{*}}\right)}{2} \\
& >\frac{u\left(q^{H}\right)+q^{A^{*}}-c\left(q^{H}\right)-q^{A^{*}}}{2}=\frac{u\left(q^{H}\right)-c\left(q^{H}\right)}{2}>0,
\end{aligned}
$$

holds. Therefore, $T U^{\prime}(1)>0$. 


$$
\begin{aligned}
& T U^{\prime}(\theta)=2[[\pi(1,1)-\pi(2,1)]+[\pi(2,2)-\pi(1,2)]] \theta-2\left[\pi(2,2)-\frac{\pi(1,2)+\pi(2,1)}{2}\right] \\
& \Rightarrow T U^{\prime}(0)<0, T U^{\prime}(1)>0
\end{aligned}
$$

Since $T U^{\prime}(\theta)$ is a continuous function, there is the minimal value of $T U(\theta)$ within the interval, $0<\theta<1$, as illustrated by Figure 3.This discussion is summarized by

\section{Theorem 4.}

There are coexistence ESSs that are inferior to the capitalist-occupying ESS. However, if the occupying ratio of artisans is sufficiently large, there are also superior frictional ESSs to the foregoing capitalist-occupying ESS.

This theorem implies that there are cases that more uniformed the social order becomes, the more efficient resource allocation is achieved even though such a society is akin to capitalist-occupying ESS. The reason is that two juxtaposing different social orders disrupt the principle of way of life.

Nevertheless, we must evoke Theorem 3. No matter how rich a society becomes, its individuals are bothered bya kind of vagueness: apathy, as Riesman (1950) dubbed. ${ }^{6}$ Because there is one factor that cannot be altered by such prosperity: social cohesion generated by sincere work and mutual respect.

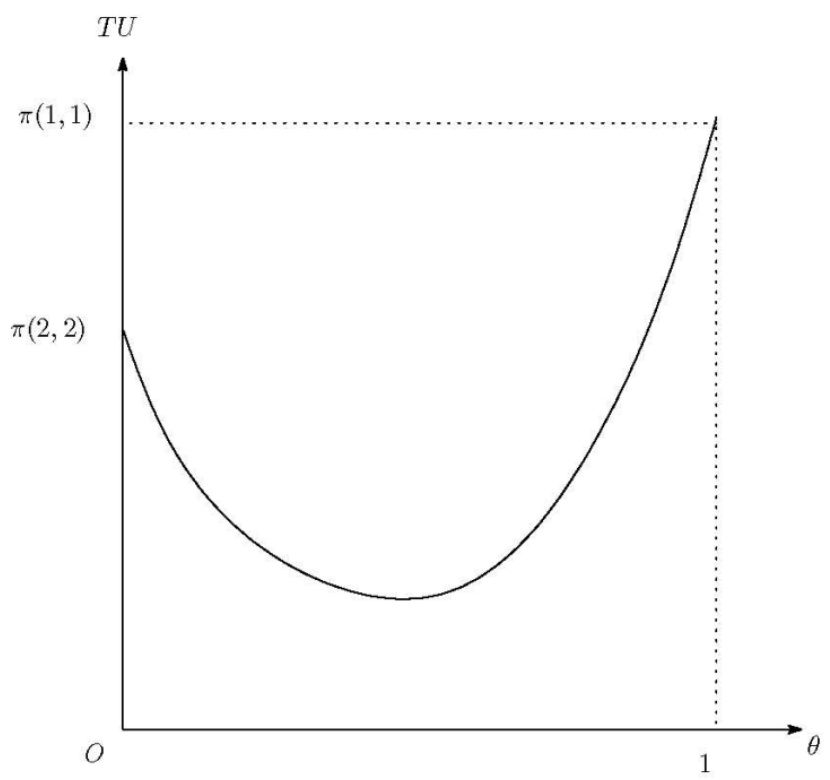

Figure3. The Total Utility

\subsection{The Role of Education and Bifurcation Theory}

As discussed in the Introduction, meritocratic education is superior to a new-artisanship education on the point of tangibility. People, who are impoverished initially, possibly feel great felicity from increased economic surplus. This undeniable fact implies that meritocratic education is easy to implement, especially in developing economies which are located at the artisanship-dominated coexisting frictional ESS wherein economic welfare is lower than that of the capitalist-occupying equilibrium.

Nevertheless, even though the prevalent meritocratic education might achieve a highly industrialized and profit-centered economy, as aforementioned, residents in such an economy are inescapable from apathy, which comes from the alienation from the society. This is because the first-best allocation is achievable only when the economy reaches the artisan-occupying ESS. Accordingly, a new type of artisanship education, which emphasizes the social contribution of one's work via nurturing mutual respectfulness caused by realizing widespread elaboration in the production process, is urgently desirable.

${ }^{6}$ Riesman also dubs one of his books (1964) “Abundance for What?" 
In general, the effect of education is discontinuous and dominates once it exceeds a threshold. Such a phenomenon is called bifurcation. Figure 4 illustrates this bifurcation wherein the coexisting frictional ESS (Point $C$ in Figure 2) vanishes, and the artisan-occupying equilibrium ensues.

The shift in function $f$ in Figure 4 is the effect of a new type of artisanship education. Whenever education is prompted to nurture artisanship, we can interpret that the value of function $\Lambda$ increases for a given $\theta$; thus, function $f$ shifts upward (from the dotted curve to the real line). Bifurcation does not occur until the upward shift is significantly large. Before the bifurcation happens, the society experiences a gradual increase in the occupying ratio of artisan $\theta$ even though the economic welfare might be aggravated conversely.

However, $\Lambda$ exceeds a certain value, and the frictional ESS, which is expressed by Point $C$, will disappear and bifurcation occurs. The society overcomes the wedge of capitalists and converges to the first-best outcome. This discussion suggests that meaningful education must endure the short-sighted criticism and be controlled and adapted from a long-term perspective that emphasizes on social cohesion sustained by sincere work.

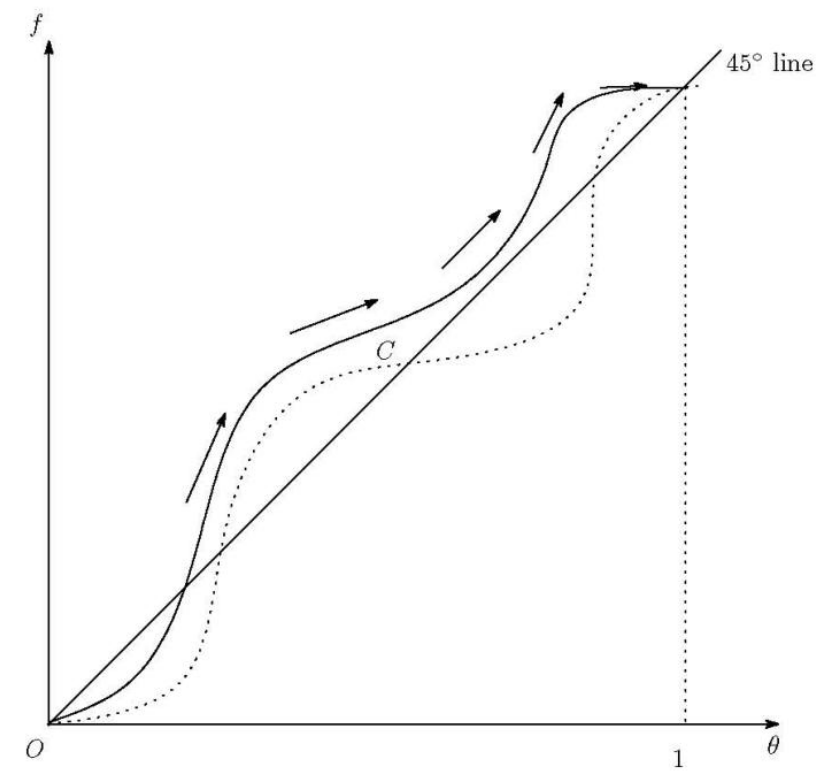

Figure4. The Bifurcation

\section{CONCLUding Remarks}

By assuming the bounded rationality of human beings, this study analyzes how a social norm is created and evolves. Education plays a crucial role in constructing an efficient social norm while the efficiency is defined more general than usual in the sense that the objective function includes not only profits but also job satisfaction. The following results have been obtained.

First, owing to their bounded rationality, when people face the choice of artisanship or capitalist life, two stable ESSs exist in a society: artisan-occupying ESS and capitalist-occupying ESS. The former ESS is Pareto superior because high-quality goods are exchanged within the society and every individual satisfied with their work. Accordingly, how to achieve an artisan-occupying society is the ultimate aim of education.

Second, artisans and capitalists coexist in reality. We have succeeded in showing the existence of such kind of ESS by extending the concept of equilibrium (i.e., frictional ESS). On the coexistence equilibrium, wherein the profit-centered strategy is the evolutionary stable strategy, an increase in the number of artisans harms the well-being of the society at least in the short run. This is because the conflict between different values becomes serious and social order is disrupted. In such a case, the society begins to feel that artisanship is out dated, and meritocratic and capitalist-promoting education gains prominence instead. This movement might be accelerated by the tangibility of meritocratic education. This phenomenon corresponds to the phase of the industrialization that Veblen (1904) criticizes. 
Finally, according to the bifurcation theory, when pragmatic and artisan-promoting education is gradually immersed, the wedge of profit-centered motive, which hinders the society from moving toward the artisan-occupying ESS, fades away. If such a tendency reaches a certain point, the society autonomously begins evolving toward the first-best outcome: artisan-occupying ESS. In this sense, true education, which aims at social cohesion by nurturing mutual respectfulness to every sincere work, requires generousness to the diversity of children and deep patience with the slow progress of reformation by its nature.

\section{REFERENCES}

Dewey, J.(1916).Democracy and Education: an Introduction to the Philosophy of Education, Reprinted by Free Press, New York, 1997.

Otaki, M. (2015). "On the Limit of Human Cognition: Is Artisanship always Dominated by Profit Motive?"'International Journal of Humanities Social Sciences and Education, Vol.2, Issue 6, pp. 49-57.

Riesman, D. (1950).The Lonely Crowd: a Study of the Changing American Character, New Heaven, Yale University Press.

Riesman, D. (1964).Abundance for What? Revised version by Transaction Publishers, New Brunswick, 1993.

Veblen, T. (1904).The Theory of Business Enterprise, reprinted by Cosimo Inc., New York, 2005.

Weibull, J. W. (1995). Evolutionary Game Theory, Massachusetts, MIT Press.

\section{AUTHOR'S BIOGRAPHY}

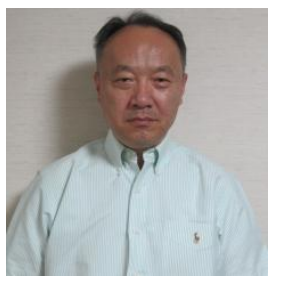

Masayuki Otaki, Ph.D, Professor of Economics, Institute of Social Sciences. The University of Tokyo.

Main Research Fields: Macroeconomic Theory; Environmental Economics; Educational Economics; Economic Thought. 